\title{
Múltiplas contingências e o processo de adaptação estratégica
}

\author{
Multiple contingencies and the process of strategic adaptation
}

\author{
Paulo Hayashi Junior \\ Doutorando do Programa de Pós-Graduação em Administração da Universidade Federal do Rio Grande do Sul (UFRGS), \\ Mestre em Administração da Universidade Federal do Paraná (UFPR), Curitiba, PR - Brasil, e-mail: paulo.hayashi@hotmail.com
}

\section{Resumo}

O artigo procura delinear de maneira exploratória um esboço acerca das múltiplas contingências que envolvem o processo de adaptação estratégica. Esse processo fica comumente restrito à díade organização/meio ambiente externo. Todavia, há muitas outras adaptações que estão envolvidas e que não costumam vir à tona nos estudos estratégicos, tais como, por exemplo, as adaptações do indivíduo, da organização e do próprio ambiente ex-ante e ex-post. Dois frameworks são propostos para tentar integrar o corpo teórico para pesquisas futuras e entrelaçamento com outras teorias, principalmente as relacionadas com a complexidade de Morin e Luhmann. É importante destacar que com as múltiplas contingências o processo estratégico e o de aprendizagem se tornam tão imbricados um no outro que as múltiplas adaptações podem ser vistas sob o ponto de vista de múltiplas aprendizagens. Assim, a estratégia não é um processo isolado que, cada vez mais, depende da negociação e da coordenação da construção de múltiplos ambientes criados pelos seus atores.

Palavras-chave: Estratégia. Ambiente. Múltiplas contingências. Adaptações. Cooperação.

\begin{abstract}
This essay tries to delineate some exploratory results about strategic process and multiple contingencies. Usually the strategic process is restricted to the dyad organization-environment. However, there are many other adaptations that are involved and which do not usually come to light in strategic studies. Two frameworks are proposed to integrate the multiple contingencies for future research and entanglements with other theories, especially those related with complexity. Other area of development is multiple contingencies and multiple learning. Strategy is not an isolated process and it does not happen just because a person. To the contrary, strategy is a process interwoven with all the stakeholders. Besides, strategic process depends on the negotiation and coordination of construction and sharing multiples enacted environments created by its actors.
\end{abstract}

Keywords: Strategy. Environment. Multiple contingencies. Adaptations. Cooperation. 


\section{Introdução}

Graças à dinâmica do ambiente externo, bem como das organizações e dos indivíduos, o processo de adaptação é constante, como num fluxo, por isso multifacetado e individual ao mesmo tempo, sincrônico e assincrônico, parcial e global, como na adaptação de vários elementos que interagem entre si, mas que apresenta certa consistência interna como as rotinas e a própria cultura organizacional, o que possibilita caracterizar certa "ordem” necessária aos sentidos e até mesmo ao crescimento. Todavia, na área organizacional o tema da adaptação e da estratégia tem sido trabalhado de modo mais restrito à díade organização/ambiente externo, sem contemplarcom maiores interesses e atenção os outros elementos ou possibilidades.

Desse modo, este trabalho visa a explorar essas outras possibilidades inerentes ao fenômeno de adaptação, principalmente quando observadas sob um olhar de "consilience" (WILSON, 1994) ou competitividade sistêmica (ESSER et al., 1996; MEYER-STAMER, 2005). Tal perspectiva enriquece a estratégia partindo de uma visão estática para uma percepção mais processual, dinâmica e integrativa, holística e dialética. Com isso, são descobertas e expostas as adaptações do indivíduo consigo mesmo, bem como da organização e também do próprio ambiente, ou seja, adaptações ex-ante e ex-post de tais elementos. Para tanto, o trabalho será desenvolvido por meio de uma breve revisão da literatura do ambiente interno e externo, suas várias camadas ou níveis, contemplando a divisão proposta por MeyerStamer (2005) e Esser et al. (1996). Para os autores, o ambiente externo pode ser dividido em quatro níveis, cada um com suas particularidades e emprestando diferentes níveis de percepção e temporalidade de percepção à organização e aos indivíduos.

Uma visão mais ampla do ambiente e dos processos de adaptação torna possível a aproximação da literatura estratégica com a complexidade da Morin ou Luhmann; todavia, não é propósito deste artigo pavimentar tal via. Por último, mas não menos importante, são apresentados dois frameworks sistêmicos integrativos sobre as adaptações estratégicas. A busca e a pesquisa por correntes teóricas diferentes, mas complementares e talvez concorrentes, justifica-se pelo fato de que uma visão mais ampla permite fazer a triangulação de diferentes abordagens teóricas e de novas percepções e poderes de análise para fenômenos complexos como a estratégia. Por fim, esmiúça-se um debate e um aprofundamento do tema com sugestão de agenda de pesquisas futuras na parte final do ensaio.

\section{O que é estratégia?}

Tanto para o economista Friedrich Hayek quanto para o teórico organizacional Chester Barnard, repousa na adaptabilidade o principal problema da organização (WILLIAMSON, 2000). Para o primeiro, a adaptação está mais relacionada à "maravilha do sistema de preço", enquanto que para Barnard a adaptação depende da coordenação interna dos fatores, sendo importantes a comunicação, a cooperação e a direção dada pelos propósitos. Além da palavra adaptação é possível usar os termos alinhamento estratégico e fitness. Todavia, todos os termos tendem a se restringir à díade organização/ ambiente externo sem explorar outras perspectivas. O planejamento estratégico, a análise SWOT e até mesmo a abordagem estratégica da visão baseada em recursos (VBR) adotam também uma postura organização/ambiente externo.

No mesmo sentido de adaptação, Mintzberg (1995, p. 22) procura dar uma definição genérica sobre estratégia como sendo: "o impulso mediador entre a organização e seu ambiente". Mas de que maneira pode ser percebido esse impulso? Como pode ser operacionalizado o impulso ou exercida a opção de adaptabilidade?

O impulso, ou melhor, a estratégia, pode ser definido por meio de cinco maneiras distintas: 1) como um plano; 2) uma posição; 3) perspectiva; 4) padrão de ação; e 5) artimanha (MINTZBERG et al., 2000; MINTZBERG, 1987).

Pode-se ver, na sequência, as definições e ilustrações acerca de cada uma delas:

1) comoplano:"estratégia refere-se aos planos da alta administração para alcançar resultados consistentes com a missão e os objetivos gerais da organização" (WRIGHT et al., 2000, p. 24). Segundo Mintzberg (1987), a estratégia como plano é feita em antecipação aos fatos e desenvolvida com consciência e com propósitos para algo; 
2) comoposição: “a estratégia é a criação de uma posição única e valiosa, envolvendo um conjunto diferente de atividades" (PORTER, 1996, p. 68);

3) comoperspectiva: uma maneira de perceber o mundo e construir uma ideologia total sobre ela (MINTZBERG, 1987). "Cada um dos grandes construtores de empresas que conhecemos - dos Médici e dos fundadores do Banco da Inglaterra até Thomas Watson da IBM... tinha uma idéia definida, na verdade uma clara 'teoria do negócio', a qual instituía suas ações e decisões” (DRUCKER, 1984, p. 71);

4) como padrão de ação: representa uma consistência de comportamento, tal qual a apresentada por Picasso ao pintar azul por um tempo ou o preto de Ford (MINTZBERG, 1987). "O freguês pode ter seu carro na cor que quiser, contanto que seja a preta" - Henry Ford (apud DRUCKER, 1984, p. 242);

5) como artimanha: refere-se a uma manobra específica com propósitos de ludibriar um oponente ou adversário. "Estratégia é quando você está sem munição, mas continua atirando para que seu inimigo não saiba" - autor desconhecido (apud ANSOFF, 1991, p. 87).

A estratégia, ainda que operacionalizada por maneiras distintas e mesmo levando à formação de diferentes "escolas", continua restrita à díade organização/ambiente externo. Como primeiro passo para extrapolar essa díade, é importante analisar o ambiente de forma mais detalhada a ponto de possibilitar uma descrição mais ampla sobre o fenômeno da adaptação. Assim, os trabalhos de Meyer-Stamer (2005) e Esser et al. (1996) sobre os diferentes níveis ambientais se tornam relevantes e úteis para adentrarmos na questão.

\section{A organização e seus ambientes}

De acordo com Esser et al. (1996), o meio ambiente pode ser operacionalizado por meio da distinção de quatro camadas ou níveis: meta, macro, meso e micro. Observe a figura seguinte:

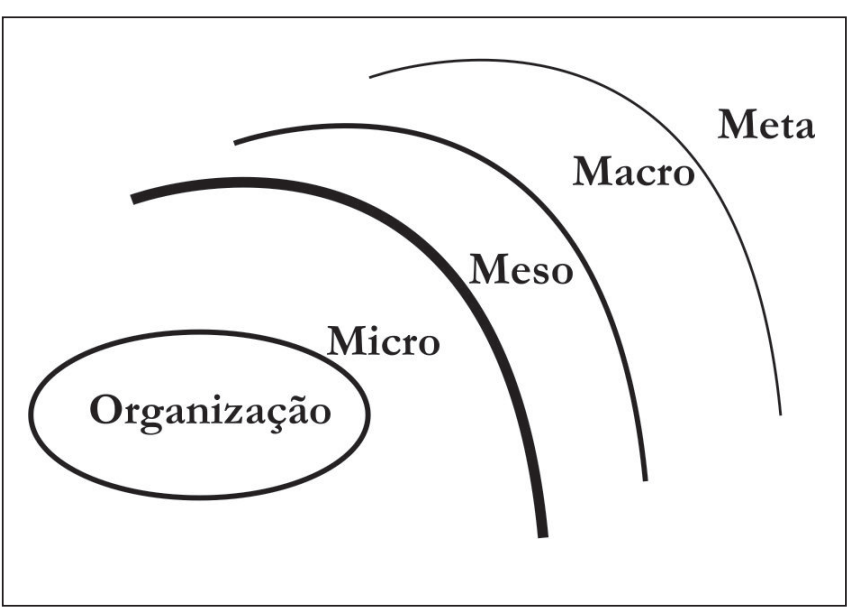

Figura 1 - A organização e seus ambientes Fonte: ESSER et al., 1996.

Uma diferença básica entre os níveis é a facilidade de percepção de mudança, bem como a ação direta ou indireta nas organizações. Níveis mais distantes tendem a ser mais sutis na mudança e na percepção, ainda que guardem elementos poderosos em alterar o comportamento e o padrão das empresas. A temporalidade também é diferente, estando os níveis inferiores mais impregnados de um tempo presente, instantâneo, do que os de níveis superiores (macro e meta).

Assim, o nível meta seria o mais difícil de perceber, mas que tem capacidade de influenciar vários setores industriais ou mesmo as indústrias. Por exemplo, a capacidade do país ou da região de criar condições para que os atores consigam mobilizar coerentemente suas ações de maneira eficaz (MEYER-STAMER, 2005; ESSER et al., 1996 ). Ou, conforme Meyer-Stamer (2005, p. 3),

primeiro, há uma questão sobre por quê alguns atores numa dada sociedade conseguem ou não ser vitoriosos em criar um ambiente favorável para os negócios. Como os atores governamentais e não governamentais interagem e eles realmente se interagem? Podem eles concordar sobre uma visão geral para onde a economia está direcionada? Os atores-chave numa sociedade compartilham orientações básicas sobre negócios privados, sobre a importância relativa 
dos mecanismos de mercado relacionados aos mecanismos de coordenação, sobre as orientações de comércio exterior (economia aberta ou fechada)? Nós chamamos isso de análise do nível meta, pois é feita além do escopo dos fatores macro-econômicos.

Por sua vez, o macroambiente é composto por elementos contextuais como economia, política, ecologia, tecnologia, cultura e também por tendências em relação ao tempo desses elementos. O macroambiente também é comumente chamado de ambiente geral e a nomenclatura dos elementos que o compõem também pode variar conforme os autores. Os mais comuns são: força, setor, condições. Dessa forma, enquanto alguns autores preferem dizer força social, por exemplo, outros utilizam condição social ou então, setor social. Veja o quadro com o resumo dos vários elementos pertencentes a esse nível vistos por diversos autores:

\begin{tabular}{llll}
\hline n. & Hatch (1997) & Wright et al. (2000) & Hall (1982) \\
\hline 1 & Setor social & Forças sociais & Condições demográficas \\
2 & Setor cultural & & Condições culturais \\
3 & Setor legal & Forças político-legais & Condições políticas \\
4 & Setor político & & Condições legais \\
5 & Setor econômico & Forças econômicas & Condições econômicas \\
6 & Setor tecnológico & Forças tecnológicas & Condições tecnológicas \\
7 & Setor físico & & Condições ecológicas \\
\hline
\end{tabular}

Quadro 1 - Resumo dos principais elementos do macroambiente

Fonte: Baseado em HATCH, 1997; WRIGHT et al., 2000; HALL, 1982.

Os elementos domacroambientenão são estáveis e, portanto, estão em constante mudança. Todavia, a percepção de tais mudanças muitas vezes não é tarefa fácil. É difícil perceber alterações do macroambiente num curto período de tempo, mas não a longo e médio prazo. O mesmo se pode dizer do nível meta. Não se pode desprezar as forças do macroambiente, pois envolvem mudanças da própria sociedade.

Já o nível meso é composto por políticas específicas que auxiliam no desenvolvimento do setor industrial ou do cluster. Por exemplo, políticas que facilitem a exportação/importação, a infraestrutura de transportes e afins. De acordo com Meyer-Stamer (2005), o nível mesoé o campo específico das políticas e instrumentos públicos ou privados de promoção e de desenvolvimento de negócios. É o nível de ligação e de interação entre o micro e o macro.

Por sua vez, o microambiente é o nível mais próximo da organização em si. $\mathrm{Na}$ verdade, ela até faz parte dele. O microambiente é composto por outras organizações e pessoas que podem afetar diretamente o desempenho da empresa, sendo suas consequências de fácil percepção e, portanto, influenciando o alcance dos objetivos programados. São elementos do microambiente: clientes, consumidores, fornecedores, concorrentes, governo, mídia, sindicato, credores e parceiros.

Em outras palavras, a empresa e o seu microambiente são formados por stakeholders, ou seja, grupos de pessoas que podem influenciar (positivamente ou negativamente) o desempenho e que têm interesse na empresa. O relacionamento com os stakeholders pode ser fundamental para o sucesso da organização, bem como para sua sustentabilidade no médio e longo prazo. Exemplos da importância desse tipo são os estudos que tratam de questões comportamentais nos custos de transação como a confiança e a presença (WILLIAMSON, 1987, 1995, 2000) ou a ausência de oportunismo (CONNER, 1991; CONNER; PRAHALAD, 1996). Numa perspectiva sistêmica é possível analisar as mediações de alguns dos principais atores envolvidos no processo estratégico de adaptação, pois eles se envolvem e são envolvidos em múltiplas contingências.

\section{Múltiplas contingências}

Mesmo que haja diferentes maneiras de operacionalizar a estratégia, bem como de verificar 
os diferentes níveis do ambiente externo (micro/ meso/macro/meta), há uma lacuna na literatura a respeito das várias adaptações inerentes ao processo de estratégia que pode ser chamado de múltiplas contingências. Existe a necessidade do indivíduo de se adaptar à estratégia, bem como a si mesmo. $\mathrm{O}$ indivíduo afetado pela estratégia inicial necessita não apenas adaptar-se a uma nova situação e contexto, mas também, e principalmente, a um novo "eu". A organização precisa se adaptar à estratégia e a si própria. Há uma adaptação do ambiente externo à estratégia da empresa por meio das reações dos seus clientes, dos competidores, etc. A figura seguinte procura ilustrar e dar uma dimensão da complexidade e das possibilidades de adaptação que envolvem um processo de mudança estratégica:

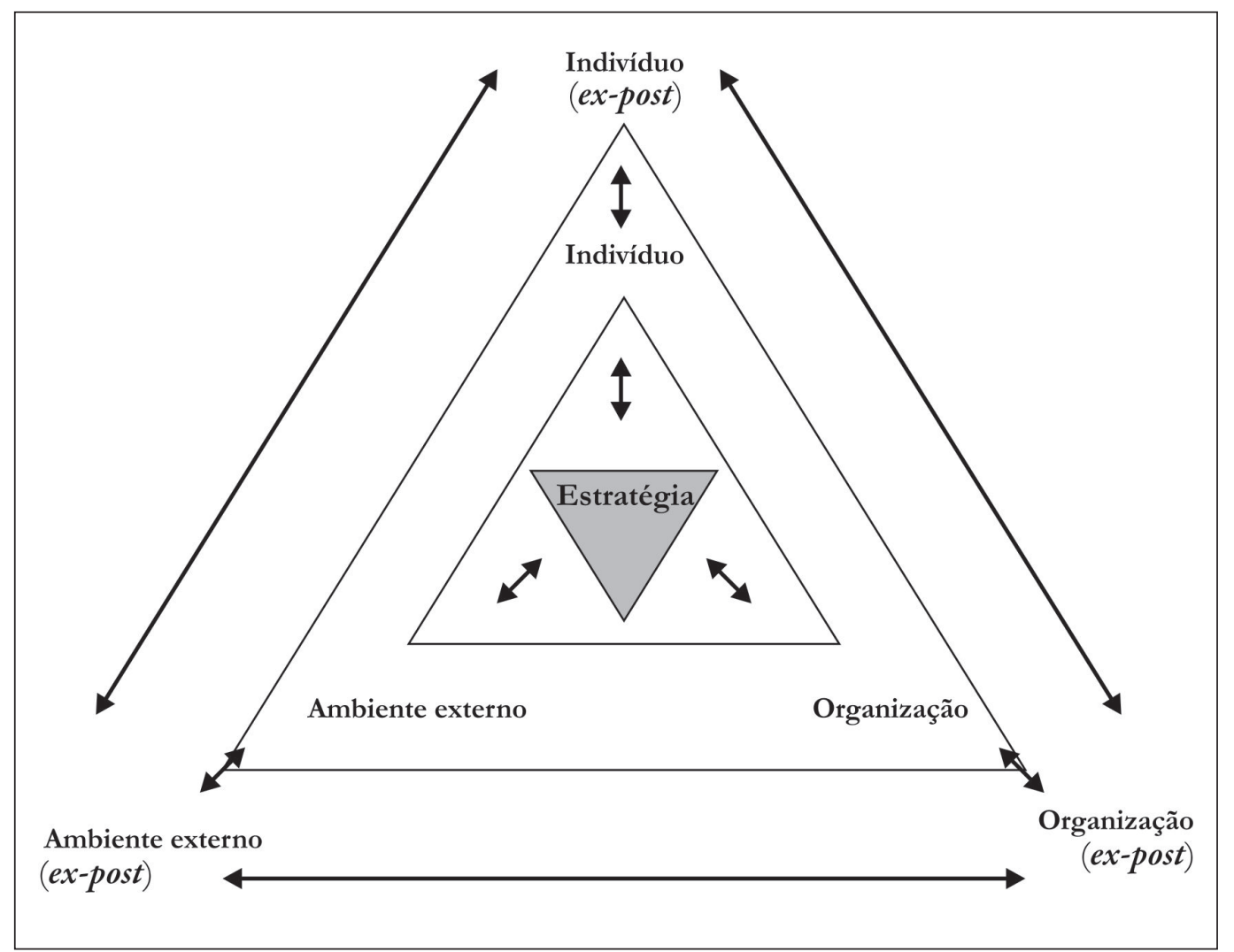

Figura 2 - Múltiplas adaptações estratégicas

Fonte: Elaboração do autor.

Graças à dinâmica, tanto do ambiente externo quanto das organizações e dos indivíduos, o processo de adaptação é constante como um fluxo, mas que mantém certa consistência interna, como rotinas e cultura organizacional. Esses são fatores que possibilitam caracterizar certa "ordem" interna necessária ao crescimento. Assim sendo, o reajustamento do sistema é necessário e principalmente perceptível em situações de mudanças drásticas ou radicais. Finalizando a questão que antes parecia apenas restrita à organização com o ambiente externo, quando analisado sob uma ótica sistêmica o número de adaptações aumenta. Desse modo, existe a adaptação do indivíduo para com uma nova organização, para com um novo ambiente externo e também para a necessidade de um novo indivíduo (ex-post). A organização deve não apenas se adaptar ao ambiente analisado (ex-ante), mas a um novo ambiente (ex-post), aos novos indivíduos e também a ela mesma (organização ex-ante e ex-post). Por sua vez, o próprio ambiente externo também precisa se adaptar a ele mesmo (ex-ante e ex-post), e a uma nova organização e novos indivíduos que a compõem. Ou seja, a primeira adaptação (estratégia clássica ambiente/organização) pode se desdobrar conforme o esquema seguinte: 


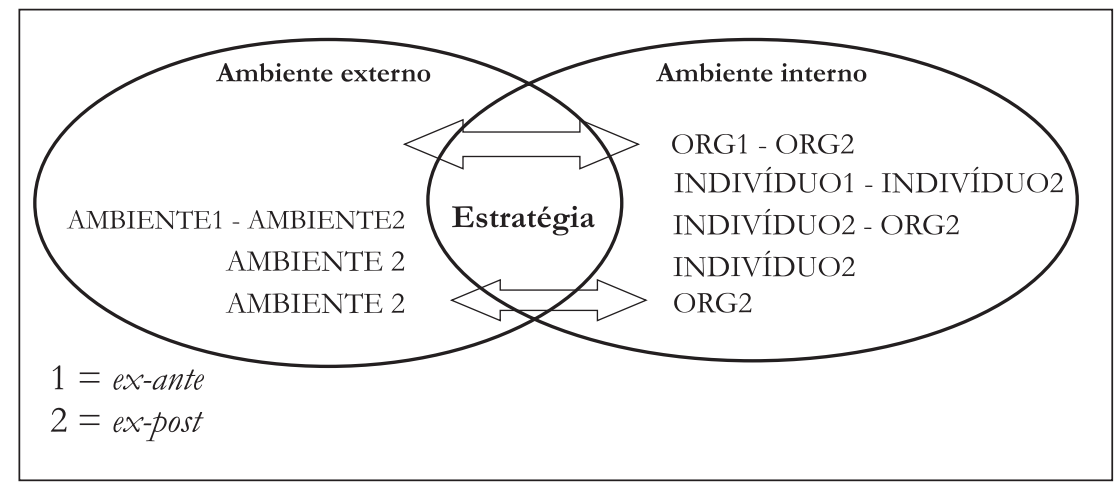

Figura 3 - Múltiplas adaptações

Fonte: Elaboração do autor.

Desse modo, aumenta-se a complexidade das adaptações estratégicas e do fenômeno da estratégia. Esta, por sua vez, não pode ser encarada por um olhar simplista de mera adaptação mecânica da organização para o ambiente externo, mas por meio de múltiplas e recorrentes adaptações, multifacetadas e fragmentadas em relação aos atores e ao tempo (ex-ante e ex-post). Por isso, costuma-se dizer que as mudanças estratégicas têm data para começar, mas não para terminar.

\section{Debates, discussões e aprofundamentos}

Os problemas de adaptação, quando vistos sob um olhar de "consilience" ou "sistêmico", tornam-se mais ricos que a visão tradicional funcionalista, principalmente por possibilitar questões de reflexão e pontos de flexão, uma vez que "o agente de mudança está imediatamente envolvido no processo de mudança e que ele molda as ações, tanto quanto é moldado por elas. A situação transforma o programa, tanto quanto o programa transforma a situação" (COOPER, 1976, p. 1002). Dessa forma, velhas dificuldades de adaptação ou de planejamento podem ser levadas em conta, principalmente no que tange à dimensão social (indivíduo/grupo) e de construção e compartilhamento/objetivação social. Por exemplo, na questão social os atores não são apenas observadores passivos, nem simplesmente elementos de transformação. Eles também observam e transformam, criam o ambiente e são também por ele criados. Há uma relação mais complexa entre observador/ realidade, transformador/transformação.

Outra aplicação dos frameworks é possibilitar uma análise de microprocessos de adaptação por meio da estratégia enquanto prática social (WHITTINGTON, 1996; WHITTINGTON et al., 2003). A visão racional do puro planejamento estratégico se torna assim limitada graças à própria natureza do objeto e de sua complexidade. Ademais, esmiúça-se a relação estratégia e a aprendizagem tão debatida entre Mintzberg (1990, 1991) e Ansoff (1991), mas cujos ensinamentos ainda precisam ser estendidos e operacionalizados.

Nas múltiplas contingências, o processo estratégico se torna um encadeamento de processos de aprendizagem/adaptação, sem que haja desmerecimento de vincular aprendizagem com estratégia ou de subordinar um ao outro. Há uma imbricação na malha fina da estratégia e da aprendizagem em diferentes níveis, tornando assim impossível separar um sem atingir ou danificar o outro. Assim sendo, é necessário refletirmos sobre as teorias que nos façam perceber com outros olhos a relação estratégia/ empresa, principalmente sem desprezar os elementos culturais, cognitivos e de construção compartilhada e ao mesmo tempo fragmentada da realidade. Cada um vê o que é possível e constrói da sua maneira.

Isso me lembra, para finalizar o artigo, uma famosa peça do escritor alemão Lessing, cujo título é Nathan, o sábio. A peça foi publicada em 1779 e versa sobre as múltiplas verdades por meio de uma fábula em que existe um anel dotado de poderes mágicos, cujo detentor é amado e querido por todos. Ele consegue viver sob o lema "amar ao próximo como a si mesmo". Todavia, o dono do anel, sentindo a iminência da morte, gostaria de compartilhá-lo com seus três filhos. Para tanto, pede para que sejam feitas duas cópias idênticas e fiéis ao original. Assim, cada um dos filhos recebe um anele nenhum deles, nem mesmo opai, sabe diferenciar qual deles é o verdadeiro. Com isso vem a necessidade da tolerância e do diálogo, do respeito e da abertura a outras verdades que não apenas a da pessoa, bem como o combate ao egocentrismo. Na peça é estimulada essa percepção da presença e influência do outro. 
Se as múltiplas contingências permitem a observação mais próxima de uma realidade complexa e multifacetada pelos diversos atores, independente do nível, é importante que os estrategistas percebam que nãoépormeio de uma construção totalitária e unilateral da estratégia que se terá os melhores caminhos, mas pela rapidez de aprendizagem e de compartilhamento de informações e comunicação para que a cooperação entre os stakeholders se torne coluna mestra para as diversas mudanças e adaptações. Além disso, a integração em face da diferenciação e das diferentes percepções e construções se torna não uma opção, mas uma necessidade para que processos de mudança aconteçam com melhores condições de sinergia e respeito. Assim, a estratégia não é um processo isolado e que, cada vez mais, depende da negociação e da coordenação da construção de uma visão compartilhada de mudanças e pontos comuns de interesses pelos seus participantes.

\section{Referências}

ANSOFF, I. Critique of Henry Mintzberg's. The design school: reconsidering the basic premises of strategic management. Strategic Management Journal, v. 12, n. 4, p. 449-461, 1991.

BACHELARD, G. A psicanálise do fogo. São Paulo: Martins Fontes, 1994.

CONNER, K. A historical comparison of resource-based view and five schools of thought within industrial organization economics: dowe have a new theory of the firm. Journal of Management, Greenwich, v. 17, n. 1, p. 121-154, 1991.

CONNER, K. PRAHALAD, C. K. A. Resource-based theory of the firm: knowledge versus opportunism. Organization Science, Providence, v. 7, n. 5, p. 477-501, 1996.

COOPER, R. The open field. Human Relations. New York, v. 28, n. 11, p. 999-1017, 1976.

DRUCKER, P. F. Introdução à administração. 2. ed. São Paulo: Pioneira, 1984.

ESSER, K. et al. Systemic competitiveness: new governance patterns for industrial development. 2. ed. London: Frank Cass, 1996.

HALL, R. Organizations: structure and processes. 2. ed. Upper Saddle River, NJ: Prentice-Hall, 1982.

HATCH, M. J. Organization theory: modern, symbolic, and postmodern perspectives. 3. ed. New York: Oxford University Press, 1997.
MEYER-STAMER, J. Systemic competitiveness revised. Working Paper Mesopartner Electronic Document, New York, v. 15, n. 3, p. 515-520, 2005. Disponível em: $<$ http://www.mesopartner.com/publications/Systemic_ revisited.pdf $>$. Acesso em: 6 dez. 2008.

MINTZBERG, H. et al. The strategic concept I: five Ps for strategy. California Management Review, v. 30, n. 1, p. 11-24, 1987.

MINTZBERG, H. et al. The design school: reconsideration of the basic premises of strategic management. Strategic Management Journal, New York, v. 11, n. 3, p. 38-48, 1990.

MINTZBERG, H. et al. Learning 1, planning 0 (reply to Igor Ansoff). Strategic Management Journal, New York, v. 12, n. 4, p. 38-49, 1991.

MINTZBERG, H. etal. Criando organizações eficazes. 2 ed. São Paulo: Atlas, 1995.

MINTZBERG, H. et al. Safári da estratégia: um roteiro pela selva do planejamento estratégico. 2. ed. Porto Alegre: Bookman, 2000.

PORTER, M. E. What is strategy? Harvard Business Review, New York, v. 12, n. 4, p. 61-78, 1996.

WHITTINGTON, R. Strategy as practice. Long Range Planning. London, v. 29, n. 5, p. 57-64, 1996.

WHITTINGTON, R.; JARZABKOWSKI, P.; MAYER, M. Taking strategy seriously: responsibility and reform for an important social practice. Journal of Management Inquery, New York, v. 12, n. 4, p. 48-55, 2003.

WILLIAMSON, O. E. The economic institutions of capitalism. 2. ed. New York: Free Press, 1987.

WILLIAMSON, O. E. Organizational theory: from Chester Barnard to the present and beyond. 2. ed. New York: Oxford University Press, 1995.

WILLIAMSON, O. E. Why law, economics and organization? Berkeley: University of California, 2000.

WILSON, E. Consiliência: a unidade do conhecimento. 2. ed. Rio de Janeiro: Câmpus, 1994.

WRIGHT, P. etal.Administração estratégica: conceitos. 2. ed. São Paulo: Atlas, 2000.

Recebido: 15/06/2010 Received: 06/15/2010

Aprovado: $16 / 08 / 2010$ Approved: 08/16/2010 